\title{
André Ventura - por Portugal pelos portugueses
}

\author{
Submetido em: $31 / 03 / 2020$, aprovado em: $12 / 08 / 2020$ \\ 10.30612/mvt.v7i13.11328 \\ José Pedro Reis ${ }^{1}$
}

RESUMO: Decorria o ano de 2017 e em Portugal discorriam as eleições para aos órgãos autárquicos locais, surgindo no meio daquele processo a figura de André Ventura que era candidato à Câmara Municipal de Loures pelo Partido Social Democrata em coligação com o Centro Democrático Social.

Iria se destacar na imprensa com as suas declarações polémicas em que iria criticar o comportamento de certas e determinadas etnias para nunca mais sair até ao momento (2020) dos holofotes mediáticos da política, como sendo o rosto da nova direita portuguesa.

Recentemente iria apresentar a sua candidatura à Presidência da República em Portugal com o seu movimento político a conseguir um novo folgo para conseguir a atenção mediática e para subir mais uns degraus da evolução desse mesmo processo que terá nestas eleiçôes, uma prova decisiva para perceber a sua real influência política..

Palavras-chave: André Ventura. Nova Direita. Candidatura.

\section{André Ventura - For Portugal by the portugueses}

ABSTRACT: The year of 2017 was taking place and in Portugal the elections for local autarchic for local autarchic bodies were taking place, in the middle of that process the figure of André Ventura, who was a candidate for the Municipal Council of Loures by the Social Democratic Center, emerged.

He would stand out in the press with his controversial statements in which he would criticize in behavior of certain and certain ethnic groups in order never to leave the media spotlight of politics until now (2020), asthe face of the new portuguese right.

Recently he was going to presente his candidacy for the Presidency of the Republic in Portugal with his political movement getting a new respite to get the media attention and to go up a few more steps in the evolution of this same process that he will have in these elections, a decisive proof to understand his real political influence.

Keywords: André Ventura. New Right. Candidacy.

1 Doutorando em História pela Faculdade de Letras da Universidade do Porto. josepedroreis88@gmail.com. Orcid: https://orcid.org/0000-0003-2850-9784. Endereço eletrônico: josepedroreis88@gmail.com. 


\section{André Ventura - Para Portugal por los portugueses}

RESUMEN: El anó 2017 estaba teniendo lugar y en Portugal se llevaban a cabo las elecciones para las autoridades locales, em medio de ese proceso surgió la figura de André Ventura, candidato al Consejo Municipal de Loures por el Partido Socialdemócrata en coalición com el Centro Socialdemócrata.

Destacaría en la prensa con sus controvertidas declaracions en las que criticaría el comportamiento de ciertos y ciertos grupos étnicos para no dejar nunca el centro de atención de los medios de la política hasta ahora (2020), como el rostro de la nueva derecha portuguesa.

Recientemente iba a presentar su candidatura a la Presidencia de la República en Portugal con su movimiento político obteniendo un nuevo respiro para llamar la atención de los medios y subir algunos pasos más en la evolución de este mismo proceso que tendrá en estas elecciones, una prueba decisiva para entender su influencia política real.

Palavras Clave: André Ventura. Nuevo derecho. Solicitude.

\section{INTRODUÇÃO}

O espetro político mundial vai admitindo grandes alteraçôes, o espaço do politicamente correto tem vindo a perder cabimento na agenda mediática e também na agenda dos partidos.

Nos últimos anos, a extrema-direita reacionária, autoritária e com determinados desses movimentos a terem particularidades fascistas tem estado em promoçáo em todo o mundo, mencionando também que já chefiam um grande número de governos de países, entre eles os mais notórios: Estados Unidos, Índia, Hungria, Turquia, Itália, Filipinas e igualmente no Brasil (LÖWY, 2019, p.25).

Intensificando o impacto deste assunto, quatro dos países mais povoados do mundo são governados por uma direita radical e autoritária, alusão para a Índia, Estados Unidos, Brasil e Filipinas. Prosseguindo com este minudenciar é essencial mencionar também o reforço na votação de Reino Unido, França e Itália, como igualmente Polónia e Hungria com Miguel Urbán a mencionar que esta a nascer uma nova vaga reacionária global para um novo ciclo político que irá se apoiar no conservadorismo revolucionário e um neoliberalismo profundamente autoritário (URBÁN, 2019, p.179).

Portugal por razões óbvias não iria escapar-se a este fenómeno crescente, referindo Enzo Traverso que as novas direitas radicais estáo representadas em todos os países da União Europeia e em oito deles ocupavam também posiçôes nos seus governos nacionais, intensificando a sua preocupação com esse fenómeno, argumentando que desde 1930 o mundo não presenciava nada semelhante com este fenómeno e fez voltar a pairar sobre o globo avantesmas antigos do fascismo (TRAVERSO, 2019, p.17).

Existe uma corrente na historiografia próxima dos estudiosos de esquerda que a dilucidação mais óbvia para fundamentar o crescimento destes movimentos, esta relacionado com a globalização capitalista, que é ponderado como um processamento de homogeneização cultural, que se produz e reproduz à escala mundial que cria formas e pavor identitários, complacentes com manifestaçóes nacionalistas e/ou religiosa de intolerância que auxiliam a conflitualidade étnica e profissional, surgindo principalmente quanto mais as nações perdem o seu poder económico, mais se ostenta a 
imensa glória da nação que esta acima de tudo (LÖWY, 2019, p.26).

O historiador Fernando Rosas menciona igualmente para aprofundar esta crise do capitalismo, como sendo potenciador do efeito populista e da nova direita, que o neoliberalismo, enquanto estratégia global do capitalismo para retorquir a esta crise, esta no centro da grande e ameaçadora modificação que, com as suas novas expressôes e recursos de preponderância e manipulação ideológica, parece abranger não só as lógicas económicas, financeiras e sociais de acumulação como estar a abrir um espaço de subversão política autoritária e antidemocrática (ROSAS, 2019, p.33).

$\mathrm{Na}$ indagação de razóes para compreender o porque do malogro deste movimento capitalista e das respetivas economias nacionais, mencionado como responsável as instituiçóes económicas que subsistiam principalmente para sacar recursos de muitos, para os distribuir por poucos, findando também por não gerarem os incentivos necessários para as pessoas pouparem, investirem e inovarem, consolidando o poder de poucos (ACEMOGLU; ROBISON, 2013, p.443).

Mantendo-se este ciclo vicioso que apenas serviu para centralização do poder em poucos constituintes da sociedade, conservando a maioria dos elementos da sociedade numa posição de obedientes, o que fez dilatar as respetivas tensôes na sociedade, pois não obtinham sinais de uma executável mudança, mas, o prosseguir deste tipo de comportamentos.

Encadeando esta argumentação é impreterível mencionar a extrema importância do sistema financeiro, especialmente o bancário que num passado recente, transformou poupanças em crédito, possibilitando o acesso fácil a esse crédito, não diligenciando a estabilidade necessária e indispensável ao sistema financeiro e iriam gerar inerentemente fluxos financeiros (RAWORTH, 2019, p.105).

Um longo decurso que está integrado em vários acontecimentos que potencializaram o exautorar da sociedade e o gradual desenvolvimento destes movimentos políticos populistas que mais não fazem do que perscrutarem as fraquezas do sistema político/económico.

O conhecido ministro das finanças grego, Yanis Varoufakis, irá ainda mencionar relativamente aos problemas relacionados com o crédito que os financeiros criaram novas formas de divida com a argumentação que o risco tinha desaparecido (VAROUFAKIS, 2015, p.29)

Porém, os supracitados fluxos financeiros não iriam ter a firmeza e a retaguarda necessária, para suster aquele movimento caso assomassem perturbaçóes financeiras e iria obviamente projetar novos problemas no futuro com graves consequências para a sociedade.

Considerando que se discorre um fenómeno político nacional é notoriamente expectante que a atenção do autor deste artigo irá incidir sobre os factos e as figuras do território nacional, porém, igualmente será realizada uma observação um pouco mais global, para abarcar a real dimensão deste fenómeno português e perceber se encontra afinidade com o que se passa em outros países, como conjuntamente perscrutar as respetivas ambiguidades para perceber o que pode ser próprio desta figura (André Ventura) e do seu percurso que estará em análise exaustiva.

\section{AS RAZÕES DA MUDANÇA GLOBAIS}

No estudo para descobrir as razóes para essas mudanças globais que favorecem a concretização de uma ofensiva neoliberal e neoconservadora, que permitiu o surgimento de movimentos de características populistas de direita, desde prontamente no plano da ideologia, a referida anteriormente hegemonia das ideias e representaçóes do mundo, mas importa também mencionar nos domínios do político, do social, do económico, ou seja, aquilo que se fortaleceu como novo paradigma a partir 
dos sombrios anos de 1980 de Thatcher e de Reagen, que só se tornou viável após duas derrotas históricas, a primeira a implosão do socialismo que conduziu consigo o descrédito, constringindo o património das esquerdas marxistas e socialistas enquanto alternativas ao capitalismo.

Expondo E. Traverso, que o que foi mencionado anteriormente, provocou o fim da identificaçáo natural das classes trabalhadoras com as esquerdas e à sua tradicional permeabilidade, possibilitando a preponderância do populismo de extrema-direita, como sucedeu no norte de Itália com a Liga ou em França com a Frente Nacional. Assentindo da entrada do neoliberalismo, em largos setores da sociedade (ROSAS, 2019, p.35).

A classe trabalhadora, que estava intimidada pela globalização e desprotegida pela social democracia, como conjuntamente o espandongar dos partidos comunistas, mormente na submissão de parte do operariado francês à Frente Nacional, derrelicto pelo Partido Comunista, em partilhar, pela esquerda e em geral também sujeitada ao centro e à incapacidade aclarar as suas lutas e sentindo-se atemorizado pelos migrantes que estáo cada vez mais presentes (HONÓRIO, 2019, p.49).

Uma inversão das prioridades, em que se deixou de questionar o capitalista pelo degradar da sociedade, um discurso comum nos meios políticos da esquerda para haver uma preocupaçáo com a imigração, uma afirmação realizada por uma antiga deputada do Bloco de Esquerda, partido representativo da extrema-esquerda.

Num segundo patamar a questão do dominó, que constituía na capitulação da social democracia internacional face ao neoliberalismo. Esvaziando as defesas do Estado social e metamorfoseando os partidos sociais-democratas num instrumento ativo das políticas económicas e sociais neoliberais. Os partidos sociais-democratas, foram se tornando partidos sociais liberais, estando na atualidade a pagar um elevado preço político por esse enfileiramento (ROSAS, 2019, p.35).

O próprio Partido Social Democrata em Portugal teve este procedimento no seu seio, com a materialização em anos anteriores, concretamente na liderança de Passos Coelho em que acolheu no seu seio bastantes neoliberais, apoiantes das respetivas práticas referidas anteriormente, consumando essa ousadia com fracos resultados eleitorais nas eleiçóes que aconteceram.

Inexequível desvincular a derrocada económico internacional, da sua possível cura que foi sendo anunciado, referência para a conjeturada austeridade que mais não fez do que exacerbar os picos de tensão e aviltar o ambiente social com a incompreensão da sociedade, os défices orçamentais iam medrando, a aludida austeridade fazia desenvolver a agonia dos bancos e da população, atingindo com desmedido impacto as economias que têm agruras crónicas e fazem com que esses países prosseguissem a sua marcha difícil no panorama global (VAROUFAKIS, 2015, p.212).

A apreciação é do antigo ministro das finanças grego Varoufakis, mas é um retrato fiel para aquilo que se passou em Portugal, com a crescente contestação popular, aconteceram várias manifestaçôes com milhares de pessoas com um discurso político duro e crítico, incriminando as más práticas do passado como consequência do degradar da economia.

Relativamente às manifestações, necessário aludir as manifestações do dia 15 de setembro de 2012 por todo o país, com dezenas de milhares de intervenientes, um movimento com pouco ou mesmo qualquer paralelismo na história contemporânea que demonstra o incremento do desprazer global nacional que coopera para o incremento da constatação e igualmente em outro patamar o dissabor com o atual sistema político fazendo com que os partidos que se colocavam no extremo 
tanto da direita como da esquerda obtivessem uma maior legitimação da sua agenda política na comunidade.

Forçoso mencionar com peculiar importância o que se passou na Europa de Leste nos anos da década de 1990, no incremento da política de direita com críticas ao comunismo porque estavam num difícil processo de transição para o capitalismo (MARTINS, 2019, p.68).

A questáo elementar que igualmente se deve ter em conta quando se cogita em restringir o défice, considerando o Prémio Nobel da Economia de 2001 Joseph Stiglitz que aumentar a austeridade apenas piorará a crise, e a esperada melhoria da situação orçamental não acontecerá (STIGLITZ, 2013, p.294). A confirmação de uma teoria referida anteriormente.

Jorge Martins alude para fundamentar o crescimento da extrema direita no ocidente, a persistência de elevadas taxas de desemprego desde os anos 1970, o aumento da sociedade que irá fomentar o discurso de incremento da criminalidade e da insegurança, consequente do agravo da situação social dos mais débeis; o fortalecimento da arguição do agravamento das condiçôes de vida das classes médias e baixas provocado pela globalização neoliberal; o incremento das rivalidades nacionais incitado pelo aumento da disputa nos mercados internacionais, as políticas autoritárias das instituiçóes da UE, incremento da corrupção e da sua perceção; o terrorismo fundamentalista e a refutação alarmista e securitária dos governos ocidentais, com a reação à maior multiplicidade étnica das sociedades ocidentais como igualmente e por último a reação face ao empoderamento das mulheres e à afirmação das minorias sexuais e raciais (MARTINS, 2019, pp.73-75).

Relativamente a prováveis obrigaçóes da UE em todo este processo de incremento da destabilizaçáo da sociedade e do seu modelo padrão, a persistente dinâmica do mesmo, que irá obstruir a obtenção de uma coesão económica e social no âmbito europeu, considerando a dissemelhança que ainda perdura entre os mercados de trabalho e os sistemas de proteção social dos Estados membros (COSTA, 2004, p.315).

$\mathrm{Na}$ temática sobre o estado social, necessário afiançar que apesar de todos os conflitos eleitorais e do jogo político partidário, esses sistemas sociais conseguem ter uma vasta anuência, sobretudo na Europa, sustentando uma ligação muito forte com a sua comunidade (PIKETTY, 2014, p.721).

Necessário o aprofundamento desta temática, com a crescente importância da UE para o espaço comum europeu, como igualmente a subordinação económica que foi profundada com o passar dos anos, com os incrementos de apoios para a realização de importantes investimentos públicos e também restruturação económica, sendo essa circunstância mais sentida nos países mais instábeis economicamente.

Seria expectável que se conseguisse uma nivelação por cima em termos económicos, porém, com a gradual incorporação de países vindos da Europa de Leste que possuíam uma economia frágil saída do comunismo (matéria abordada anteriormente neste artigo), irá advir precisamente o inverso com a gradual segregaçáo entre o norte e o sul da Europa, incito de rivalidades antigas, que força o crescimento do espaço de manobra para o surgimento de partidos antissistema, alicerçando que o atual sistema político e económico que tenta ser imposto na globalidade esta comprometido.

Persistente a posição de André Ventura em se comprovar como antissistema, irá referir na sua apresentação de candidatura à Presidência da República, um marcante fundamento relativamente a este ponto: "Entre aquilo que os comentadores dizem e aquilo que as pessoas pensam vai uma enorme separação. E as pessoas precisam cada vez mais de alguém que seja a voz delas, um cidadão comum que se insurge contra este sistema político" (EXPRESSO, 01.03.2020). 
A legitimação de toda arguição referida precedentemente, da degradação das relaçóes entre a sociedade e os partidos políticos mais moderados, surgindo um novo tipo de ligaçóes para com a comunidade que esses novos partidos e movimentos mais radicais iriam procurar explorar e conseguir retirar os respetivos dividendos políticos.

\section{O QUE É O CHEGA?}

Autenticado como o $24^{\circ}$ partido português em abril de 2019 pelo Tribunal Constitucional, o Chega viria a alcançar um lugar no Parlamento logo nas eleições legislativas de 6 de outubro, tendo André Ventura sido eleito deputado pelo círculo eleitoral de Lisboa, o maior do país (CHEGA)

Um acontecimento que teve um relevante acontecimento no dia 22 de janeiro de 2019 com a entrega das necessárias 7500 assinaturas para a concretização daquele projeto político, mencionando a jornalista, São José Almeida especialista em política nacional, que o único impedimento constitucional para a criação de um partido era ter um ideário fascista, algo que naquela conjuntura da história tinha sido reconhecido, porém, iria assegurar que o problema do Chega era outro, sendo o primeiro partido assumidamente populista de extrema-direita em Portugal, sendo um modelo de outros movimentos políticos e partidos europeus (PÚBLICO, 26.01.2019).

Relativamente às assinaturas, a imprensa iria anunciar em grande escala a provável falsificação de assinaturas, nomeadamente em órgãos de informação credíveis como a TSF a exporem que haviam subscritores com 8 e mesmo com 114 anos, mencionando igualmente que das 8312 assinaturas, após serem dissecadas apenas foram validadas 6.499, as restantes 1813 foram consideradas irregulares.

Num esforço para expurgar a situação foram entregues mais 2223 a subscrever a criação do partido, mas inclusivamente nesse momento 826 voltaram a ostentar problemas, totalizando 2600 assinaturas irregulares.

Sucedendo uma postura do Chega, bastante omissa e pouco colaborativa para descortinar essa situação, não reconhecendo quem tinha concebido toda aquela confusão, náo mencionando como obtiveram as supramencionadas assinaturas, como igualmente as responsabilidades dos subscritores em todo o processo (TSF, 26.04.2019)

No jornal Público será aludido em 26 de abril de 2019 que havia inclusivamente no role daquelas assinaturas além dos mencionados menores de idade, alusão igualmente para vários falecidos, fundamentando André Ventura essa situação com a afirmação que alguém tentou prejudicar o partido. Os restantes fundadores do Chega iriam referir que tinham sido enganados, náo questionando a boa-fé de quem conduziu o processo de recolha das respetivas assinaturas.

Afiançando também André Ventura que ia entregar todos os envelopes que tinham recebido pelo correio e quando as pessoas que causaram este problema fossem identificadas iriam ser processadas (PÚBLICO, 26.04.2019).

No seu próprio site, o partido define-se como um partido político de base e natureza fundamentalmente popular que nascia da profunda incapacidade dos partidos e movimentos políticos presentes em lidar com as rápidas mudanças em curso por toda a Europa, quer a nível económico-financeiro, quer do ponto de vista ético e sociológico (CHEGA). A continua exploraçấo dos elementos incompreendidos da sociedade em proveito deste projeto político.

$\mathrm{Na}$ indagação por mais elementos identificativos da sua política, abordando a temática dos imigrantes subsiste uma preocupaçáo do Chega em aplicar medidas fortes para consolidar a diferença 
entre os nativos portugueses e os outros elementos da sociedade, com regras mais apertadas para a obtenção da nacionalidade portuguesa, defendendo igualmente a revogação da Lei de Género e Igualdade e o fim das ideologias de género e inclusivas na educação em Portugal (JUP, 14.03.2020).

A aplicação de um marketing político combativo com cartazes com mensagens fortes e de rutura da sociedade, corroborando a teoria de que uma imagem possui capacidade de derrubar certezas enraizadas na personalidade do comum cidadáo (RAWORTH, 2018, p.23). Aglutinar em seu torno todos aqueles que se identificavam com os movimentos políticos do passado para os fazer mudar para o seu partido.

Considerando que se perguntássemos a um português se seria possível um partido com este ideal político conseguir um desenvolvimento continuo na agenda política, seguramente a resposta seria negativa, considerando o claro predomínio político de dois partidos políticos, o Partido Socialista e também o Partido Social Democrata.

O Partido Socialista tem peculiar relevância na agenda política de partidos da nova direita, pelas suas persistentes críticas ao socialismo, responsabilizando esses movimentos políticos, como sendo responsáveis pela crise atual que consentiu o seu surgimento.

Um partido que tem tido um desenvolvimento exponencial, cavalgando na onda do descontentamento, com o próprio André Ventura a assegurar que num só dia, no seu partido podem-se inscrever mais de 300 militantes (OBSERVADOR, 01.03.2020).

Para quem não entende a realidade politica portuguesa, esse número de 300 novos militantes pode ser encarado com subtileza, ponderando que é um número manifestante curto, atendendo que existem aproximadamente 10 milhões de habitantes no país, mas, se abordarmos muito sumariamente as dinâmicas de mobilizaçáo de militantes para as votaçóes realizadas recentemente no Partido Social Democrata para a escolha do seu novo líder, entre Rui Rio e Montenegro, partido do qual se desfiliou André Ventura, várias foram as concelhias do pais em que não foi possível obter sequer esse número de votantes (referência para os supostos 300 militantes), conseguindo assim o Chega, num dia arrecadar mais militantes que muitas concelhias do país do PSD conseguem aglomerar ao longo da sua atividade política em vários meses ou anos, podendo ser inquietante para os dirigentes do PSD esta observação.

Não se deve desconsiderar o processo eleitoral do PSD que até há pouco tempo era o partido das massas populares, conquistando um eleitoral muito extenso em que a referida conquista se auxiliava na habilidade de agregar dos seus dirigentes locais e a presenciar a reduzida capacidade atual com várias delegaçóes concelhias a terem apenas meia dúzia de votantes nesses processos internos de eleição.

Perante a situação que se vivia no PSD, histórico participante da política lusa, confrontando com o crescimento exponencial do Chega, torna-se exequível afirmar que este último vivia um bom momento.

Averiguando esta dinâmica de crescimento, André Ventura refere mais informaçôes mencionando que o seu partido superou os 10 mil militantes e vai a caminhar para os 15 mil e elucida que muitos dos seus novos militantes assumem que entregaram o seu cartáo de militante de anteriores partidos, desde o PSD, CDS e PCP (SOL, 11.03.2020). 


\section{RETROSPETIVA HISTÓRICA DA DIREITA PORTUGUESA}

Os movimentos de direita radical iriam ter terreno fértil para progredir segundo Riccardo Marchi sobretudo devido às constantes críticas internacionais à faceta imperial de Portugal, no final de 1960, como igualmente com os massacres de Angola em 1961 (MARCHI, 2016, p.384).

$\mathrm{Na}$ pesquisa por mais referências e progredindo um pouco no tempo, Zarco Moniz Ferreira era um dos elementos importantes dos movimentos nacionalistas portugueses na década de 1970 e funda nos finais dessa mesma década o movimento Ordem Nova com a sua organizaçáo a aproximar monárquicos integralistas, ultraconservadores e neonazis, numa mistura de nacionalismos revolucionários e antiparlamentares. Os seus lideres, eram Moniz Pereira, Luís Fernandes, Gilberto Santos e Castro que foi o fundador dos comandos portugueses, e nessa fase da história cria o Centro de Estudos Renovação, do qual faziam parte João Alarcão e Nuno Barbieri e não esquecendo a figura de José Valle de Figueiredo (SANTOS, 2019, p.222).

Figuras do movimento político de extrema direita nacional, com Nuno Barbieri e José Valle de Figueiredo a ficar conectados com os movimentos anticomunistas que iriam surgir em pleno período revolucionário português.

O historiador Riccardo Marchi expóe que o progressivo desaparecimento dos nacionalistas radicais nos anos da transição para a democracia que se devia, não ao desaparecimento do regime autoritário, mas à ausência da principal causa do seu surgimento e mobilizaçáo: a luta integracionista pelo Império, não sendo na prática uma falta de sustento, mas sim uma falta de causa (MARCHI, 2016, p.408).

O pós 25 de Abril de 1974 irá ser um marco profundo e de fratura para os movimentos políticos na sua globalidade pois era findar com o partido único que tinha vigorado até aquela fase da história, como igualmente o processo de criar um partido era relativamente simples, chegavam simplesmente 5000 mil assinaturas de cidadãos maiores de 18 anos, ter estatutos, apresentar uma sigla, denominação e o respetivo símbolo com o cuidado que não fossem iguais ou semelhantes a quaisquer outros partidos precedentemente inscritos, possibilitando que em janeiro de 1975 fossem legalizados 16 partidos (LISI; FREIRE, 2015, p.47).

A extrema direita não teve circunstâncias para granjear espaço no período de consolidação do regime (1976-1980), porque a direita a anexou, com o anticomunismo a ter os seus protagonistas dentro do parlamento (HONÓRIO, 2019, p.54).

Estava latente na política portuguesa a necessidade de importunar o Partido Comunista Português pela sua antecedente postura de pretender liderar o processo revolucionário.

As bandeiras daqueles movimentos extremistas eram principalmente, influenciar o processo de descolonização no sentido de assegurar a manutenção da sua presença portuguesa em África e evidentemente impedir a crescente ameaça comunista e sovietização portuguesa (MARCHI, 2012, p.75)

Perquirindo por mais referências sobre a restrição que os partidos conectados com a direita e com tendências para se aproximar do setor mais radical, concretamente o Partido Liberal, o Partido do Progresso, o Movimento Nacionalista Português, o Partido da Democracia Cristã que seriam oficialmente dissolvidos com o acossamento aos seus líderes que iriam acabar na sua maioria detidos, perdendo o partido as suas instalaçóes e muitas delas foram depredadas pelo povo (PINTO, 1989, p.203).

Todavia, existem apontamentos na historiografia que aclaram o inverso com alusóes para o Movimento Nacionalista que nasceu em 1973, todavia entre 1976 a 1980 que a ação do MN mais 
se irá fazer sentir principalmente com as manifestaçôes que irá organizar em Lisboa no dia 10 de Junho, tendo a sua sede funcionado num rés do chão da Rua Tomás Ribeiro com os seus elementos mais destacados a serem Nuno Rogeiro e Vítor Luís Rodrigues (SANTOS, 2019, p.219).

Procurando mais referências sobre o comportamento político da direita no pós-25 de Abril em especial nos momentos críticos da revolução, Jaime Nogueira Pinto, o reconhecido historiador português e conectado com estes movimentos políticos irá mencionar que era fácil de compreender que o 25 de Abril trouxe consigo um decisivo abalo no quadro político da direita com o regime vencido e também a crescente radicalização do processo político militar, com os vários atos do 28 de Setembro de 1974 e também com o 11 de Março de 1975 (PINTO, 1989, p.202).

Todavia em agosto de 1974, a SEDES publicou um estudo sobre os partidos políticos constituídos na alvorada do 25 de Abril e foram analisadas 48 formaçóes políticas e eis que 10 delas seriam posicionadas nas áreas de centro, de direita e de extrema-direita, minudenciando mais esta observação Riccardo Marchi que irá referir que três eram de centro, quatro de centro direita, seis de direita e cinco de extrema direita (MARCHI, 2012, p.75)

Uma nova organização surgiu em 1977, todavia acabaria de forma rápida, chamava-se Frente Nacional e era liderada por Guedes da Silva (SANTOS, 2019, p.220).

Um importante apontamento deve ser realizado, não esquecer o MIRN (Movimento Independente para a Reconstrução Nacional) que foi dos movimentos mais recordados na cultura popular segundo Jaime Nogueira Pinto que irá referir sobre aquele movimento: "O MIRN apresentou-se como muito liberal para a direita que pretendia liderar e demasiado reacionário para o sistema” (SANTOS, 2019, p.224).

Na temática do MIRN, o seu líder Kaúlza de Arriaga capitalizava para si o prestigio de ter sido preso durante bastante tempo, após o 25 de Abril de 1974 sem ter culpa formada, porém, conforme foi referido no parágrafo anterior, as suas dinâmicas seriam frágeis e não iriam conseguir quebrar a hegemonia de outros movimentos, como também alguns tabus políticos existentes (PINTO, 1989, p.206).

O maior tabu político existente foi naturalmente a aversão que os portugueses iriam mimosear à ditadura de direita que tinham vivido no passado e que tinha durado várias décadas, consumando vários momentos negativos de um passado que ainda era bastante recente naquele momento da história.

Surpreendentemente a extrema direita esteve a um passo do Parlamento Português na década de 1979, algo que a maior parte da historiografia nacional não menciona, referência para o resultado do Partido da Democracia Cristá, que tinha Silva Resende e Pinheiro de Azevedo que iria lançar uma lista de independentes, mas que simpatizavam com a direita. Acabaria por Manuel Couto Viana em Viana do Castelo ficar a 1000 votos da eleição e em Lisboa ficariam a uns meros 2000 votos (SANTOS, 2019, p.114).

Uma análise rápida dos resultados em arquivo na Comissão Nacional de Eleiçóes é possível perceber que aquele partido teve em Viana 2483 votos, 1,7\% das eleiçóes, num total de pouco mais de 145 mil votantes, sendo a 4 o força mais votada.

Relativo ao distrito de Lisboa é forçoso salientar que iriam conseguir obter 12 mil votos e conquistar praticamente $1 \%$ da votação, tendo também mais votos que alguns partidos do lado oposto da barricada nomeadamente o PCTP/MRPP.

Investigando por mais referências a nível nacional sobre aquele ato eleitoral não deverá ser insondado que este partido, teve resultados entre os $0.5 \%$ até atingir o seu expoente máximo nos 8,97\% no circulo de eleiçóes fora da Europa (COMISSÃO NACIONAL DE ELEIÇÓEES). 
Interpretando estes resultados e fazendo uma crítica aos mesmos, necessário salientar que poderá passar escasso, considerando que votaram 6 milhôes de pessoas e a referida votação foi menor do que 100 mil votos, porém, não podemos ignorar que a própria eleição de deputados é materializada através de círculos eleitorais e arriscaria funcionar a influência local, principalmente nos círculos eleitorais mais pequenos, além de que neste momento da história portuguesa tinham passado apenas 5 anos da revolução do 25 de Abril e havia ainda um grande fulgor político com uma grande atividade dos partidos de esquerda e particularmente de extrema esquerda.

Alongando esta dissecaçáo para compreender este excelente resultado, se considerarmos vários resultados de movimentos de extrema direita pela Europa, vários foram os movimentos que tiveram apenas 0,1\% dos votos em eleiçóes legislativas que ocorreram na Europa (MARTINS, 2019, pp.242-280).

Nos anos seguintes, em 1987 existem referências para o surgimento de outros movimentos da extrema direita, concretamente a Nova Monarquia que foi convidada pelo CDS de Adriano Moreira a integrar as listas às legislativas, conseguindo ostentar oito candidatos, desenvolvendo grande parte da sua campanha no sul do país, contudo, o CDS conseguiria apenas $4 \%$ e este movimento não iria eleger nenhum deputado.

A sua existência seria curta, expondo Miguel Castelo Branco seu antigo membro: "a Nova Monarquia quis constituir-se em partido político, mas foi alvo de ataque de intensos por parte de Freitas do Amaral, bem como da extrema esquerda portuguesa. Foi intencionalmente confundido com um movimento neofascista e racista. A Nova Monarquia acaba em 1991, devido ao coro de ataques cerrados. Não tinham meios para o refutar um a um” (SANTOS, 2019, p.227).

Entrando no novo milénio, surgiu o PNR (Partido Nacional Renovador) em 12 de abril de 2000 que iria avassalar este espetro político da direita radical nas várias eleições que se realizaram até um passado mais recente concretamente até à entrada em cena do Partido Chega.

\section{QUEM É ANDRÉ VENTURA?}

A figura de André Ventura obteve grande evidência na opinião pública pela forma bastante espicaçada com que defendia o seu clube sendo ele um mediático adepto do Sport Lisboa e Benfica.

$\mathrm{Na}$ exploração por mais dados sobre a sua pessoa, uma boa solução é consultar o site do próprio Partido Chega para mencionar alguns apontamentos biográficos, tais como ser licenciado e doutor em Direito, tendo sido professor na Universidade Nova de Lisboa e na Universidade Autónoma de Lisboa, sendo também consultor de diversas empresas na área jurídica, não dessabendo a sua passagem pela Autoridade Tributária e Aduaneira.

Não ignora a sua passagem por vários órgãos distritais do PSD e da JSD, tendo sido Conselheiro Nacional de 2015 a 2017, tendo sido identicamente candidato por aquele partido à Presidência da Câmara Municipal de Loures em 2017, tendo conseguido um dos melhores resultados de sempre do PSD no Concelho (CHEGA).

Relevante mencionar que esse processo eleitoral iria deixar marcas na coligação CDS com o PSD que eram os partidos que apadrinhavam a sua candidatura, as críticas ao seu discurso que manteve contra os ciganos, fizeram com que o CDS lhe tivesse arredado o apoio, mantendo-se o mesmo apoio do PSD por obstinação de Passos Coelho que teve a oposição de vários elementos carismáticos do seu partido (PÚBLICO, 26.01.2019). 
Ventura assume que aquela campanha foi o seu verdadeiro nascimento político, a conjuntura de viragem política, compreendendo que tinha posiçóes completamente dissemelhantes ao que defendia o PSD (SOL, 11.03.2020).

Uma inserção ao populismo, que segundo alguns autores pode ser definido como: uma posição política que apoia o povo contra a elite, o que é valido para quase todos os movimentos ou partidos políticos e que o seu emprego nos partidos de extrema direta favonia aqueles movimentos pela sua persistente crítica aos elementos que são contra o povo, sendo também um ataque às politicas neoliberais da Europa (LÖWY, 2019, p.26).

Comparativamente ao populismo de André Ventura que o próprio assume que tem de ser os portugueses a decidirem se o querem ou não no Parlamento, quando é questionado se o populismo deve ou náo ser travado (SOL, 11.03.2020). Uma resposta que atesta o uso do populismo pela sua pessoa e que somente os eleitores o poderão sancionar.

O próprio Ventura era um outsider da política, certo que teve cargos em partidos políticos, porém a sua vertente política era quase ignota da comunidade no seu geral, um importante lembrete para a questão do outsider político que terá auxiliado também por exemplo a eleição de Bolsonaro que era ele igualmente um outsider dos grandes palcos (LEIRIA, 2019, p.116).

Ultimamente, no mês de março de 2020, o candidato irá assumir em entrevista que era irrealizável alguém governar à direita sem o Chega e assumia que tinha votos de racistas e fascistas (JORNAL ECONÓMICO, 13.03.2020). Porém, segundo o próprio não se identificando com nenhum rótulo que seja de extrema direita, muito menos com neonazismos (SOL, 11.03.2020).

Uma figura que se envolve em constantes polémicas, porque naturalmente terá percebido que senão alentasse polémicas, seria seguramente apenas mais um político e iria passar despercebido na bruma dos partidos e da história, uma das várias polémicas em seu torno foi quando assumiu a um órgão de comunicação social que iria ser um deputado em exclusivo e, mas, na prática não o iria ser porque iria manter-se como consultor e comentador televisivo (EXPRESSO, 29.02.2020).

\section{RESULTADOS ELEITORAIS}

Procurando um paralelismo com o comportamento eleitoral dos portugueses e o que se passa em Espanha em torno deste tipo de partidos, subsiste um ponto de desequilíbrio que contraria a questão dos votos dos menos favorecidos economicamente em André Ventura.

No Vox as regióes com mais poder de compra em que o respetivo rendimento médio dos seus habitantes desses municípios era superior a media nacional, a percentagem de votos no Vox dobrou se comparado com os votos registados no resto do território, sugerindo Miguel Urbán que é um ativista político que ocorre um vínculo significativo entre os rendimentos altos e o apoio à extrema-direita no país vizinho (URBÁN, 2019, pp. 182-183).

Indagando por mais referências para fundamentar esta argumentação e característica portuguesa, em Lisboa o concelho em que os seus habitantes tem mais poder de compra em média em Portugal, o Chega iria ter apenas 4 mil votos, se gerarmos um paralelismo com o Iniciativa Liberal que é outro dos movimentos que tem surgido no movimento político da direita e com a cultura popular a caracterizá-lo como sendo um partido próximo das classes mais abastadas a obter ter mais do dobro dos votos, sendo na prática 11.891 ficando a escaços votos do triplo.

No vizinho concelho de Oeiras que se encontra no terceiro lugar do ranking nacional, segundo a PORDATA, novamente o IL a ter o dobro dos votos do Chega. 
Nos arredores da capital do país, nas áreas suburbanas com graves problemas sociais e económicos, os resultados são inversos ao que sucedeu em Lisboa, com o Chega a ter mais votos que o Iniciativa Liberal na Amadora, Sintra, Odivelas, Loures, Vila Franca de Xira, Sintra, entre outras. Chegando em alguns casos a ser praticamente o dobro dos votantes do Chega comparativamente aos votantes do Iniciativa Liberal.

Atestando as difíceis situaçôes financeiras e sociais dos concelhos onde André Ventura iria conseguir os seus resultados eleitores, José Santa Pereira refere que a maioria dos votantes eram desempregados, sem formação superior (OBSERVADOR, 01.03.2020).

Indagando pelas realidades existentes em outros concelhos mais distantes de Lisboa, para compreender se é uma dinâmica nacional o apoio dos elementos da sociedade com mais capital ao Iniciativa Liberal e obviamente os maus resultados do Chega nesses territórios, em S. João da Madeira no distrito de Aveiro, relevante polo industrial do país, os resultados são semelhantes com o IL a ter 128 votos e o Chega simplesmente 65, num total de 11 mil votantes.

No ranking dos cinco concelhos com mais poder de compra dos seus habitantes, concretamente o segundo, referência para o Porto deve haver especial atenção para a análise dos seus resultados eleitorais, principalmente pela longa tradição do Porto em ser apreciado como o bastião do liberalismo, do progresso económico do país e onde naturalmente os ideais do Iniciativa Liberal tinham grande facilidade em implementar-se e conquistar espaço político ao Chega, conseguindo uma diferença abismal de votação, $2.81 \%$, enquanto o Chega teve apenas $0,44 \%$, com dados mais concretos 3 mil e 77 votos de diferença em 129 mil votantes.

Um último apontamento para terminar esta análise, com José Santa Pereira a referir no jornal online Observador que o partido em análise conquistava ter uma maior atração de votos no sul do país nos concelhos do Alentejo e do Algarve, sendo um padrão que tinha sido reconhecido nas eleições europeias de maio de 2019 (OBSERVADOR, 01.03.2020).

Abordando rapidamente a história política portuguesa faz com que esta observação seja bastante importante, porque o Alentejo sempre foi considerado uma região com forte influência do Partido Comunista Português que esta naturalmente colocado no expecto oposto da política nacional.

$\mathrm{Na}$ abordagem a esse crescente predomínio do Chega no Alentejo, o líder deste partido irá assumir que tem recebido transferência direta de militantes do PCP para o Chega, confirmando toda a arguição referida anteriormente (SOL, 11.03.2020).

Evidentemente que esta informação não pode ser confirmada, porque não existe informação sobre a distribuição geográfica dos militantes pelo território nacional, mas que poderá ter de facto comprovação porque conforme foi referido anteriormente os votos naquele partido naquela região estão em crescendo.

Profundas mudanças estão a ocorrer na política nacional que são reforçadas se atendermos à mais recente sondagem da Intercampos, empresa de sondagem conceituada em Portugal, realizada em fevereiro de 2020 que atribuiu uma votação de 6,1\% ao partido de Ventura, o que intensifica o seu crescimento com 1,29\% das últimas eleições (JUP, 14.03.2020).

O próprio assume em entrevista que deseja ser a terceira ou a quarta força política, admitindo que irá suplantar o PCP, o PAN e mesmo o CDS e no espaço de oito anos ser o maior grupo parlamentar (SOL, 11.03.2020). 


\section{PARALELISMO COM OUTROS MODELOS DA NOVA DIREITA INTERNACIONAL}

A agenda de André Ventura capitaliza para a política nacional a persistente preocupação com a corrupção e a falência do estado, indicando consecutivamente as suas falhas na esperança de as explorar em seu proveito.

Relativamente à corrupção, existe um ponto em comum na agenda política de um outro elemento da política da nova direita, concretamente de Bolsonaro que conseguiu também manipular a indignação popular contra esse tipo de práticas.

$\mathrm{Na}$ indagação por mais pontos de equilíbrio, temos o constante ódio à esquerda, ou ao centro esquerda, sendo ainda mais surpreendente, na medida em que a Guerra Fria findou há décadas, a União Soviética não existe mais e obviamente que não encontra expressividade relevante na política nacional (LÖWY, 2019, p.28).

Fazendo uma indagação mais ampla e procurando pontos de equilíbrio constantes, temos a questão do autoritarismo, a fidelidade a um "homem forte", um líder capaz de "restaurar a ordem", a ideologia opressiva, o apoiante da violência policial, o apelo ao restabelecimento da pena de morte e a distribuição de armas pela população para se defender de possíveis atos e indivíduos criminosos e a intolerância com as minorias sexuais, especialmente os elementos das organizaçóes de apoio a essas minorias, com a espera de explorar os setores religiosos reacionários de várias confissóes religiosas (LÖWY, 2019, p.29).

$\mathrm{Na}$ temática da violência polícia, é elementar referir o seu constante apoio aos elementos das forças policiais, preocupando-se em passar uma mensagem que lhe seja amiga, não terá sido por mero acaso que em quanto passeava com os seus apoiantes pela cidade de Portalegre nas horas anteriores a anunciar a sua candidatura para Presidente da República os primeiros lugares que visitou foi uma esquadra da Polícia de Segurança Pública naquela cidade e seguiu-se um posto da Guarda Nacional Republicana (EXPRESSO, 01.03.2020).

Procurando por uma comparação realizada pelo seu próprio líder, afirma que o Chega, não tem irmãos siameses na Europa, não existem partidos iguais ao Chega, que o mesmo nasce de algo muito especifico do que é ser português, da corrupção, da impunidade e do abandono do Estado a algumas regióes (JORNAL ECONÓMICO 13.03.2020).

Existe uma extrema dificuldade de André Ventura em assumir parecenças de projetos políticos internacionais, tentando passar uma imagem de ser um movimento único, numa das entrevistas menciona sobre esse ponto: "Os políticos acham que usar a linguagem comum e usar propostas comuns é ser populista... a verdade é que a classe média está a pagar para quem não quer fazer nada." (SOL, 11.03.2020).

\section{CANDIDATURA À PRESIDÊNCIA DA REPÚBLICA}

No dia 29 de fevereiro, em Portalegre, perante centenas de apoiantes, André Ventura anunciou que seria candidato às eleiçóes presidenciais em janeiro de 2021. Deixando no panorama político bastante expectativa para perceber o que iria ser conseguido naquele novo patamar político.

A candidatura foi apresentada naquela cidade, porque foi naquele distrito que o seu partido teve o seu melhor resultado percentual 2.73\% a nível nacional obtendo 1407 votos em 51600 votantes, alcançando excelentes resultados ficando inclusivamente à frente do PAN (Partido Animais 
e Natureza), partido que ficou no resultado nacional à sua frente, como também foram apenas 554 votos que o separaram do CDS, partido histórico da política nacional do CHEGA, atendendo a todos estes resultados, o seu líder André Ventura simplesmente se poderia orgulhar e sobretudo se refletirmos sobre a média de idade dos seus habitantes que é bastante elevada e obviamente menos recetiva à mudança.

Tentando perceber os resultados nos outros concelhos do distrito, obteve mais votos que o Iniciativa Liberal em: Alter do Chão, Arronches, Avis, Campo Maior, Castelo de Vide, Crato, Elvas, Fronteira, Gavião, etc., ficando também próximo o CDS e por vezes teve inclusivamente mais votos que o PAN que era até há pouco tempo, o partido que parecia ser capaz de quebrar com os ritmos do sistema político português que estavam implementados.

Faltando apenas um elemento para conseguir comprovar a sua afeição para territórios com baixo poder de compra, Portalegre ocupa o $23^{\circ}$ lugar nacional, todavia, Alter do Cháo ocupa o $178^{\circ}$ lugar, Arronches $187^{\circ}$ lugar, Avis 166 lugar, Campo Maior 54 lugar, Castelo de Vide $123^{\circ}$ lugar; Crato $181^{\circ}$ lugar; Elvas $78^{\circ}$ lugar; Fronteira $138^{\circ}$ lugar e por fim Gavião em 190º lugar.

Ocupando lugares mediano para o fundo da tabela no ranking nacional que é constituído por 308 municípios com a exceção da própria Portalegre, Campo Maior e também Elvas que estão nos primeiros 100 lugares do ranking.

No seu discurso de apresentação de candidatura irá manter a sua postura ofensiva, nunca defensiva, mantendo-se como contestatário, aludindo que iria entrar um diploma no Parlamento para legalizar a prisão perpétua para homicidas e pedófilos, referindo-se também ao atual Presidente da República como sendo: "é uma espécie de avozinho dos portugueses", referindo-se a uma outra possível candidata, Ana Gomes, histórica militante do Partido Socialista afirmando que iria ser dizimada (EXPRESSO, 01.03.2020).

Explorando a revolta dos portugueses irá expor também no seu discurso: "Enquanto houver portugueses a ganhar pensôes de 100 euros, estaremos nas tintas para a Constituição. Enquanto houver políticas agredidos nos seus quartéis, professores, bombeiros e profissionais e saúde, estaremos nas tintas para Constituição, enquanto nos disserem que não podem haver leis sérias contra a corrupção, nós estamos nas tintas para a Constituição" (EXPRESSO, 01.03.2020).

Persistente a exploração da revolta, do mal-estar na sociedade e principalmente dos elementos que contribuem para esse mal-estar, referindo frases como: "Nós estamos aqui nos últimos 45 anos é que sabemos", "vivemos num país autocrático", colocando enfâse na Constituição como sendo uma espécie de bíblia nas palavras do próprio que não serve para os dias de hoje, terminando com a afirmação que se estava nas tintas para a Constituição e para o Marcelo Rebelo de Sousa (EXPRESSO, 01.03.2020).

A mais recente sondagem, irá atribuir a André Ventura uma percentagem de 9,3\%, o que é demonstrativo do constante crescimento da sua imagem (EXPRESSO, 01.03.2020).

Será um importante momento para compreender a força do seu projeto político e a dimensão do mesmo, embora o mesmo prossiga cada vez mais centrado na sua imagem o que poderá ser nefasto no futuro, potencializando o possível fim do Chega caso, André Ventura por alguma razão se retire da politica.

O próprio legitima isso afirmando que as pessoas podem não conhecer o partido de que é líder, mas conhecem-no a si e sabem aquilo que pensa (SOL, 11.03.2020). 


\section{CONCLUSÃO}

Um relevante apontamento para abordar o Chega para iniciar a sua conclusão: "A história não se repete: podemos encontrar semelhanças ou analogias, mas os fenómenos atuais são bem diferentes dos modelos do passado Acima de tudo, não temos - ainda - Estados totalitários comparáveis aos da pré-guerra... Em todo o caso, não é relevante no mundo de hoje, onde não existe uma "ameaça revolucionária", sem mencionar o facto óbvio de que o grande capital financeiro demonstra pouco entusiasmo pelo "nacionalismo" da extrema direita- mesmo que esteja pronto para se adaptar a ele, se necessário (LÖWY, 2019, p.27).

O sistema capitalista, em especial em temos de crise, concebe e reproduz constantemente fenómenos como o fascismo, golpes de Estado e regimes autoritários, ponderado que a raiz dessas tendências é sistémica e a alternativa deve ser radical, isto é antissistema (LÖWY, 2019, p.29).

Reforçando essa argumentação que a globalização capitalista se transforma também num processo brutal de homogeneização cultural, conducentes a manifestaçóes nacionalistas e/ou religiosas de intolerância auxiliando a conflitualidade étnica e confessional, quanto mais se perde o poder económico, mais se proclama a imensa glória da nação, sobretudo todas temáticas e problemas (ROSAS, 2019, p.37).

Escrevia-se em 2019 que havia fracas hipóteses em Portugal para uma direita radical populista nacional-identitária ganhar importância na política nacional ao ponto de ser poder, não existia qualquer ameaça de invasores, nem vagas de migrantes nem comunidades islâmicas que amedrontam o que quer que seja, como também não existe uma crise nem debate na esfera da política da direita sobre a identidade nacional, com a importante questão da adaptação das quatro décadas de capacidade de adaptação da direta clássica (HONÓRIO, 2019, p.51).

Evidentemente que não poderemos fazer esta avaliação pelos resultados eleitorais, não subestimar um partido ou movimento porque teve apenas 67 mil votos na globalidade do país, enquanto conseguiram 5 milhóes de votantes, deve ser tida em atenção que este número tem vindo em crescendo, porque se realizar um paralelismo rápido com as eleiçóes para o Parlamento Europeu, a força em que André Ventura foi candidato conseguiram 49 mil 496 votos.

Poderemos argumentar que os portugueses não o tinham familiarizado com aquele projeto político que era liderado por dois partidos praticamente marginais do espectro político português, concretamente o PPM (Partido Popular Monárquico) e o PPV/CDC (Partido Cidadania e Democracia Cristâ), mas, separados por apenas alguns meses, houve um incremento de praticamente 20 mil votos.

Um desenvolvimento que é essencial referir que é bastante raro de acontecer, principalmente quando envolve novos atores políticos em que normalmente após um excelente resultado, os resultados seguintes são desastrosos e por vezes fazem com que essa aventura ou mesmo projetos partidários tenham uma vida efémera. Perante isto, a atenção deverá esta voltada para os próximos resultados eleitorais e perceber as suas dinâmicas.

Numa questão importante que serão tempos exigentes para a esquerda, tempos de compreender a disputa pelo futuro para a reivindicação do seu lugar no combate ao capitalismo, com a capacidade de convocar todas e todos (HONÓRIO, 2019, p.51).

Um fortalecimento na argumentação da necessidade de um novo plano económico, procurando introduzi-la novamente no seio da sociedade, concretizando novas formas de pensar e atuar (RAWORTH, 2017, 38). 
O economista Thomas Piketty na temática do capitalismo reforça que no passado para combater as crises, concretamente no período entre guerras e também no pós-guerra era plausível considerar que a soluçáo para os problemas do capitalismo era um aumento sem limite do peso do Estado e das suas despesas sociais, porém, no presente as opçóes são forçosamente mais complexas (PIKETTY, 2014, p.715)

A solução não passa pelo ataque feroz que tem vindo a ser materializado na praça pública, nos locais de debate político, como também na imprensa, ultrapassa o limitar e corrigir as falhas, revelando sobretudo que este modelo político ainda tem legitimidade para orquestrar o futuro da sociedade.

A jornalista São José Almeida irá mencionar que o populismo se peleja defendendo as regras e enobrecendo os princípios da democracia liberal na sua diversidade inclusiva (PÚBLICO, 26.01.20219).

Eliminando falhas, tornando uma sociedade mais equilibrada e com a soluçáo dos seus problemas mais comuns este partido ficará sem agenda, será imperioso uma nova economia que seja mais distributiva, regenerando-se, não autorizando que a riqueza produtiva continue a ficar apenas e somente na máo de alguns, permitindo um crescimento económico apoiado sobretudo ambiental que será essa uma das bandeiras políticas e geracionais dum futuro bastante próximo (RAWORTH, 2018, p.186).

Não consentindo evidentemente que sejam eles a resolver os problemas, que afetam a sociedade que o mesmo faz questão de reforçar como tendo surgido nos últimos 45 anos (SOL, 11.03.2020). Não sendo uma data inusitada atendendo que se refere ao 25 de Abril de 1974 a data de mudança de um regime ditatorial para a atual democracia.

Um último apontamento para afirmação de Varoufakis que menciona que os grandes saltos da humanidade foram ocasionados por crises insuportavelmente dolorosas que fizeram com que a maioria das pessoas quisesse poder refugiar-se no passado, fundamentando que as crises sobre a história como laboratórios do futuro (VAROUFAKIS, 2015, p.43).

Uma crise especialmente económica, que se difunde para a sociedade e respetivamente política, que compromete e pode condenar algumas das conquistas democráticas e do estado social conseguidas anteriormente, obrigando obviamente a um esforço redobrado para ser incrementada uma mudança profunda, foi referido anteriormente que era necessário circundar o avanço destas forças de protesto, pouco sumo político que recruta engenhosamente nos elementos da sociedade que estão revoltados com o rumo da política/económica, eliminando as falhas e lacunas destes, o espaço vital destes movimentos de nova direita pura e simplesmente desaparecem.

\section{BIBLIOGRAFIA}

ACEMOGLU, Daron; ROBISON, James. Porque falham as naçóes?. Lisboa: Circulo de Leitores, 2013.

ALMEIDA, São José. "Chega um partido populista de extrema-direita a Portugal”. PÚBLICO, 26.03.2020, disponível em https://www.publico.pt/2019/01/26/politica/opiniao/Chega-partido-populistaextremadireita-portugal-1859410. Acesso em março 28.2020 
BARBOSA, Maria. André Ventura é candidato a Presidente. Quem são os que o apoiam?. OBSERVADOR, 01.03.2020, disponível em https://observador.pt/2020/03/01/andre-ventura-e-candidato-a-presidente-quem-sao-os-que-o-apoiam/. Acesso em março 26, 2020.

CHEGA, Site oficial do partido. Disponível em: https://partidoChega.pt/o-presidentel. Acesso em 27.03.2020

CLARO, Luís. "André Ventura "Quero ficar à frente do PCP nas próximas eleições". SOL 11.03.2020, disponível em https://sol.sapo.pt/artigo/688687/andre-ventura-quero-ficar-a-frente-do-pcp-nas-proximas-eleicoes. Acesso em março 28, 2020.

COELHO, Liliana; LIMA, Rosa Pedroso. "As contradiçôes do candidato Ventura”, Expresso, 29.02.2020, disponível em: https://expresso.pt/politica/2020-02-29-As-contradicoes-do-candidato-Ventura. Acesso em março 19, 2020

Comissão Nacional de Eleiçōes, disponível em http://www.cne.pt/sites/default/files/dl/resultados ar 1979. pdf. Acesso em março 25, 2020

COSTA, Carla Guapo Economia e Política da Construçáo Europeia: os desafios do processo de integraçáo. Lisboa: Terra Mar, 2004.

GUEDES, Nuno. "Assinaturas do Chega sob suspeita e falsificação. Havia subscritores com 8 e 114 anos. TSF 26.04.2019, disponível em: https://www.tsf.pt/politica/assinaturas-do-Chega-sob-suspeita-de-falsificacao-havia-subscritores-com-8-e-114-anos-10834602.html. Acesso em março 27, 2020

HONÓRIO, Cecília. Direitas e populismo: UE e Portugal. In: PENICHE, Andrea; HONÓRIO, Cecília; LOUÇA, Francisco; ROSAS, Fernando; FALCÃO, José; LEIRIA, Luís. (org.). Combates contra a extrema-direita: Homenagem a José Carvalho nos 30 anos do seu assassinato. Lisboa: Ediçóes Combate, 2019.

LEIRIA, Luís. Jair Bolsonaro: a extrema-direita toma o Governo do Brasil. In: PENICHE, Andrea.; HONÓRIO, Cecília; LOUÇA, Francisco; ROSAS, Fernando; FALCÁO, José; LEIRIA, Leiria. (org.). Combates contra a extrema-direita: Homenagem a José Carvalho nos 30 anos do seu assassinato. Lisboa: Ediçôes Combate, 2019.

LISI, Marco; FREIRE, André. O nascimento da democracia portuguesa: as eleiçôes legislativas de 1976. In LISI, Marco. (org.) As eleiçóes legislativas no Portugal Democrático (1975-2015). Lisboa: Assembleia da República, 2015.

LISI, Marco; FREIRE, André. Os anos de transição: as eleições para a Assembleia Constituinte. In LISI, Marco. (org.) As eleiçóes legislativas no Portugal Democrático (1975-2015). Lisboa: Assembleia da República, 2015.

LÖWY, Michael. A extrema-direita: um fenómeno global. In: PENICHE, Andrea; HONÓRIO, Cecília; LOUÇA, Francisco; ROSAS, Fernando; FALCÃO, José; LEIRIA, Luís. (org.). Combates contra a extrema-direita: Homenagem a José Carvalho nos 30 anos do seu assassinato. Lisboa: Ediçóes Combate, 2019.

MARAFONA, Marta. "Pequenos Partidos: como o CHEGA quer construir um Portugal mais conservador. JUP, 14.03.2020, disponível em https://www.juponline.pt/politica/artigo/34750/pequenos-partidos-como-o-Chega-quer-construir-um-portugal-mais-conservador.aspx. Acesso em março 20, 2020.

MARCHI, Riccardo. As direitas radicais na transição democrática portuguesa (1974-1976). Ler História, Lisboa, nº63,75-91, 2012.

MARCHI, Ricardo. Império, Naçáo, Revoluçáo: As direitas radicais portuguesas no fim do Estado Novo (1959-1974). Lisboa: Texto Editores, 2016. 
MARTINS, Jorge. A extrema direita e a direita radical nos países da União Europeia. In: PENICHE, Andrea; HONÓRIO, Cecília; LOUÇA, Francisco; ROSAS, Fernando; FALCÃO, José; LEIRIA, Luís. (org.). Combates contra a extrema-direita: Homenagem a José Carvalho nos 30 anos do seu assassinato. Lisboa: Edições Combate, 2019.

MARTINS, Jorge. Porque cresce a extrema direita?. In: PENICHE, Andrea; HONÓRIO, Cecília; LOUÇA, Francisco; ROSAS, Fernando; FALCÃO, José; LEIRIA, Luís. (org.). Combates contra a extrema-direita: Homenagem a José Carvalho nos 30 anos do seu assassinato. Lisboa: Ediçóes Combate, 2019.

MENDES, Filipa; MARTINS, Ruben. "MP investiga 2600 assinaturas irregulares para a criação do Chega”. Público, 26.04.2019, disponível em https:/www.publico.pt/2019/04/26/politica/noticia/Chega-apresenta2600-assinaturas-irregulares-criacao-partido-1870574. Acesso em março 26, 2020

MONTEIRO, Fábio. "Ventura não despe pele de deputado, chama "avozinho" a Marcelo e promete "dizimar" Ana Gomes". EXPRESSO, 01.03.2020, disponível em https://expresso.pt/politica/2020-03-01-Ventura-nao-despe-pele-de-deputado-chama-avozinho-a-Marcelo-e-promete-dizimar-Ana-Gomes. Acesso em março 27, 2020.

PIKETTY, Thomas. O capital no século XXI. Lisboa: Circulo de Leitores, 2014.

PINTO, Jaime Nogueira. A direita e o 25 de Abril. In COELHO, Mário Batista. (org.) Portugal: O sistema político e constitucional 1974/87. Lisboa: Instituto de Ciências Sociais da Universidade de Lisboa, 1989.

RALHA, Leonardo. "André Ventura: "Vamos ter a segunda volta mais espetacular da democracia". Jornal Económico, 13.03.2020, disponível em: https://jornaleconomico.sapo.pt/noticias/andre-ventura-vamos-ter-a-segunda-volta-mais-espetacular-da-nossa-democracia-558745. Acesso em março 21.2020.

RAWORTH, Kate. Economia Donut - Sete formas de pensar como um economista do século XXI. Lisboa: Circulo de Leitores, 2018.

ROSAS, Fernando. O autoritarismo pós-liberal. In: PENICHE, Andrea; HONÓRIO, Cecília; LOUÇA, Francisco; ROSAS, Fernando; FALCÂO, José; LEIRIA, Luís. (org.). Combates contra a extrema-direita: Homenagem a José Carvalho nos 30 anos do seu assassinato. Lisboa: Ediçôes Combate, 2019.

SANTOS, Pedro Marta. A extrema direita em Portugal (Dos meados de 1970 a meados dos anos 1990). In: PENICHE, Andrea; HONÓRIO, Cecília; LOUÇA, Francisco; ROSAS, Fernando; FALCÃO, José; LEIRIA, Luís. (org.). Combates contra a extrema-direita: Homenagem a José Carvalho nos 30 anos do seu assassinato. Lisboa: Edições Combate, 2019.

STIGLITZ, Joseph. O Preço da Desigualdade. Lisboa: Bertrand Editora, 2013.

TRAVERSO, Enzo. Os novos «sonâmbulos» frente ao pós-fascismo. In: PENICHE, Andrea; HONÓRIO, Cecília.; LOUÇA, Francisco; ROSAS, Fernando; FALCÃO, José; LEIRIA, Luís. (org.). Combates contra a extrema-direita: Homenagem a José Carvalho nos 30 anos do seu assassinato. Lisboa: Ediçōes Combate, 2019.

URBÁN, Miguel. Vox no Contexto Europeu. In: PENICHE, Andrea; HONÓRIO, Cecília; LOUÇA, Francisco; ROSAS, Fernando; FALCÃO, José; LEIRIA, Luís. (org.). Combates contra a extrema-direita: Homenagem a José Carvalho nos 30 anos do seu assassinato. Lisboa: Ediçóes Combate, 2019.

VAROUFAKIS, Yanis. O Minotauro global: os Estados Unidos, a Europa e o futuro da economia global. Lisboa: Bertrand Editora 2015. 